\title{
Deficiência de cobre e zinco em cabras no nordeste do Brasil
}

Sara Vilar Dantas Simões", Lucas da Costa Dutra, Karla Campos Malta, David Bezerra Assunção Kessuane de Arruda, José Ferreira Neto, Ricardo Barbosa Lucena

Departamento de Ciências Veterinárias, Centro de Ciências Agrárias, Universidade Federal da Paraíba (UFPB), Areia, PB, Brasil

*Autor correspondente

e-mail: saravdsimoes@gmail.com

\section{Resumo}

Os minerais estão presentes em todos os tecidos e fluídos do corpo e são necessários em diversos processos essenciais à vida. Dependendo se estão presentes em maiores ou menores quantidades são classificados, respectivamente, como macro ou micro minerais. 0 cobre $(\mathrm{Cu})$ e o zinco $(\mathrm{Zn})$ são micro minerais, sendo importantes cofatores de enzimas em numerosas rotas metabólicas. O cobre é necessário para o crescimento e formação de ossos, bainha de mielina, incorporação de ferro na hemoglobina, absorção de ferro do trato gastrointestinal e transferência do ferro dos tecidos para o plasma. As enzimas dependentes de Zn estão envolvidas no metabolismo de macro nutrientes e na replicação celular. 0 zinco é necessário para a reparação de tecidos e desempenha um papel vital na síntese proteica. Os sinais associados às deficiências de Cu incluem anemia, desordens ósseas, insuficiência cardíaca, distúrbios gastrointestinais, ataxia neonatal, despigmentação e crescimento anormal de pêlo ou lã. Os sinais da carência de Zn incluem emagrecimento, diarreia, pêlo áspero, perda de pêlo e lesões de paraqueratose da pele. Relata-se dois casos de deficiência de cobre e zinco em cabras, SRD, adultas, procedentes do município de Remígio/PB. As cabras foram atendidas em agosto de 2016, no Hospital Veterinário da UFPB,com histórico de emagrecimento e queda de pelo na região do flanco, dorso e parte coxa há três meses. No exame físico foram identificadas áreas de alopécia e hiperqueratose, mucosas rosa-pálidas e frequência cardíaca de $120 \mathrm{bpm}$. Sangue, soro e fragmentos da pele foram encaminhados para análise. Anemia, leucocitose e dermatite linfohistoplasmocitária com acantose, hiperceratose e espongiose foram diagnosticadas. A dosagem de minerais por espectroscopia de absorção atômica revelou baixas

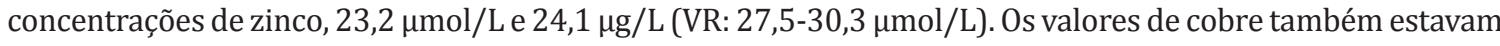
baixos, 7,3 $\mu \mathrm{mol} / \mathrm{L}$ e 8,6 $\mu \mathrm{mol} / \mathrm{L}$, (VR: 9,4-23,6 $\mu \mathrm{mol} / \mathrm{L}$ ). Quando um oligoelemento é deficiente produz-se uma síndrome característica que reflete as funções específicas do nutriente no metabolismo do animal. Os sinais clínicos de anemia, perda de peso e queratinização da pelagem eram compatíveis com a deficiência 
de $\mathrm{Cu}$ e Zn. Os achados histopatológicos e os baixos níveis séricos dos minerais comprovaram a suspeita clínica. Diversas outras manifestações clínicas associadas à deficiência de minerais têm sido identificadas na região, especialmente as relacionadas ao cobre, cobalto, sódio, cálcio e fósforo, o que sugere que na região há importantes deficiências minerais. É preocupante o fato de que a prática de mineralização não é realizada em muitas propriedades, especialmente em relação à utilização de microelementos. Na maioria das propriedades apenas o sal comum é esporadicamente disponibilizado. A dependência quase exclusiva da forragem, em solos pobres em minerais, não permite que os animais tenham atendidas suas necessidades minerais e surgem, assim, os quadros clínicos associados a essas. 